\title{
Erratum to: Adrenal steroid hormones and ethanol self-administration in male rhesus macaques
}

\author{
Christa M. Helms • Byung Park • Kathleen A. Grant
}

Received: 3 December 2013 / Accepted: 12 April 2014 / Published online: 16 July 2014

(C) Springer-Verlag Berlin Heidelberg 2014

\section{Erratum to: Psychopharmacology}

\section{DOI 10.1007/s00213-014-3590-6}

The units in several figure legends were incorrect in the original publication. Here are the corrections:

In Fig 2. Aldosterone (ng/ml) should read "Aldosterone (pg/ml)".

In Fig 4. Aldosterone (ng/ml) should read "Aldosterone $(\mathrm{pg} / \mathrm{ml})$ ".

In Fig 5. Baseline aldosterone (ng/ml) should read "Baseline aldosterone (pg/ml)".

In Fig 6. 12-month aldosterone $(\mathrm{ng} / \mathrm{ml})$ should read "12-month aldosterone (pg/ml)".

The online version of the original article can be found at http:// dx.doi.org/10.1007/s00213-014-3590-6.

C. M. Helms $(\bowtie) \cdot$ K. A. Grant

Oregon National Primate Research Center, Oregon Health \& Science

University, Beaverton, OR 97006, USA

e-mail: helmsc@ohsu.edu

B. Park

Public Health \& Preventive Medicine, Oregon Health \& Science

University, Beaverton, OR 97006, USA

K. A. Grant

Department of Behavioral Neuroscience, Oregon Health \& Science

University, Beaverton, OR 97006, USA 